\title{
ANATOMÍA E HISTOQUÍMICA FOLIAR Y CAULINAR DE MORINGA OLEIFERA (MORINGACEAE)
}

\author{
Moringa oleifera (MoringaceAe): LeAf AND STEM ANATOMY AND \\ HISTOCHEMISTRY
}

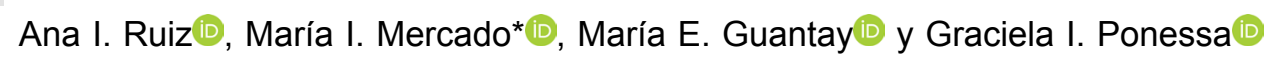

Instituto de Morfología Vegetal, Área Botánica, Fundación Miguel Lillo, Miguel Lillo 251 (T4000JFE) San Miguel de Tucumán, Argentina.

*mimercado@lillo.org.ar

Citar este artículo

RUIZ, A. I., M. I. MERCADO, M. E. GUANTAY \& G. I. PONESSA. 2019. Anatomía e histoquímica foliar y caulinar de Moringa oleifera (Moringaceae). Bol. Soc. Argent. Bot. 54: 325-343.

DOI: http://dx.doi. org/10.31055/1851.2372.v54. n3.25357

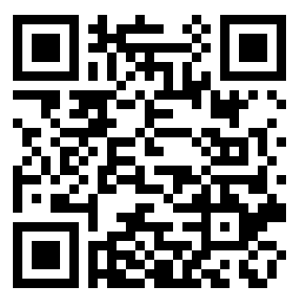

Recibido: 8 Abril 2019

Aceptado: 15 Agosto 2019

Publicado: 30 Septiembre 2019

Editora: Ana María Gonzalez (D)

ISSN versión impresa 0373-580X ISSN versión on-line 1851-2372

\section{SUMMARY}

Background and aims: Moringa oleifera, is a tree grown in tropical and subtropical regions. Valorized for its multiple uses as ornamental, food, fodder, medicinal and industrial plant, it has been recently included in the Argentinean Food Code. The objective was to study the foliar and caulinar anatomy and histochemistry of $M$. oleifera specimens cultivated in Tucumán, Argentina in order to indicate diagnostic value characters for their identification.

M\&M: The samples were analyzed under standard techniques for optical and electronic microscopy.

Results: $M$. oleifera presents pinnately compound leaves. Leaflets with pinnate, camptodromous-brochidodromous venation. Epicuticular waxes, eglandular trichomes; actinocytic and anomocytic stomata; dorsiventral mesophyll with collateral vascular bundles. Glandular fields formed by stipitate extrafloral nectaries, glandular trichomes and unicellular non-glandular trichomes. Petiolule, rachis and petiole with circular to sub-circular shape, vascular system formed by a solitary vascular bundle or a ring of collateral vascular bundles, surrounded by sclerenchyma. Stem and petiole medulla with secretory ducts containing proteins, alkaloids, mucilages and lipids. Stem cortex with crystalline idioblasts (solitary calcium oxalate crystals). Idioblasts with phenols, tannins, saponins, triterpenes, polysaccharides and proteins were observed in leaflet, petiolule, petiole, rachis and stem.

Conclusions: The foliolar architecture, the presence of glandular fields, the histology of the nectaries, and the petiole; as well as the histochemistry of its aerial vegetative organs is described for the first time for $M$. oleifera. The characters of diagnostic value are: trichomes, glandular fields, extrafloral nectaries, idioblasts and secretory ducts.

\section{KEY WORDS}

Extrafloral nectary, histochemistry, leaf architecture, Moringa, morpho-anatomy, stem.

\section{RESUMEN}

Introducción y objetivos: Moringa oleifera, es un árbol cultivado en regiones tropicales y subtropicales. Valorado por sus múltiples usos ornamentales, alimenticios, forrajeros, medicinales e industriales, ha sido recientemente incluido en el Código Alimentario Argentino. El objetivo fue estudiar la anatomía e histoquímica foliar y caulinar de ejemplares de M. oleifera, cultivados en Tucumán, Argentina y señalar caracteres de valor diagnóstico para su identificación.

M\&M: Las muestras fueron procesadas mediante técnicas estándares para microscopía óptica y electrónica.

Resultados: $M$. oleifera presenta hojas compuestas, pinnadas con folíolos de venación pinnada, camptódroma-broquidódroma. Lámina foliar con ceras epicuticulares, tricomas eglandulares, estomas actinocíticos y anomocíticos, mesofilo dorsiventral con haces colaterales e idioblastos. Campos glandulares formados por nectarios extraflorales estipitados, tricomas glandulares y eglandulares. Peciólulo, raquis y pecíolo presentan contorno circular a sub-circular, con un haz o un anillo de haces colaterales, delimitados por esclerénquima. Médula de pecíolo y tallo con conductos secretores, conteniendo proteínas, alcaloides, mucílagos y lípidos. Idioblastos cristalíferos (cristales solitarios de oxalato de calcio) presentes en el cortex del tallo. Idioblastos con fenoles, taninos, saponinas, triterpenos, polisacáridos y proteínas, en foliólulo, peciólulo, raquis, pecíolo y tallo.

Conclusiones: Se describe por primera vez para $M$. oleifera, su arquitectura foliolar, la presencia de campos glandulares e histología del nectario y del pecíolo; así como, la histoquímica de sus órganos vegetativos aéreos. Los caracteres de valor diagnóstico para $M$. oleifera son: tricomas, presencia de campos glandulares, nectarios extraflorales, idioblastos y conductos secretores.

\section{Palabras clave}

Histoquímica, arquitectura foliar, morfo-anatomía, Moringa, nectarios extraflorales, tallo. 


\section{INTRODUCCIÓN}

La familia Moringaceae (orden Brassicales) comprende un único género, Moringa, representado por 13 especies de climas tropicales y subtropicales (Verdcourt, 1985; Olson, 2002), con diversos hábitos de crecimiento como hierbas, arbustos y grandes árboles (Olson \& Razafimandimbison, 2000; Olson, 2001a, b).

Moringa oleifera Lam., es un árbol de porte mediano, originario de los bosques caducifolios del noroeste de la India y este de Pakistán (Haines, 1922), actualmente cultivado en regiones tropicales y subtropicales de todo el mundo (Olson, 2002; Kasolo et al., 2010; Olson \& Fahey, 2011).

Qaiser (1973) describe hojas de hasta $60 \mathrm{~cm}$ de largo, escasamente tomentosas en el haz y glabros en el envés, en tanto May Ling (2004) cita presencia de nectarios extraflorales (NEF) en la base de cada folíolo.

En los últimos años, M. oleifera ha recibido una creciente atención por sus múltiples usos ornamentales, alimenticios, forrajeros, medicinales e industriales (Cáceres et al., 1991, 1992; Makkar \& Becker, 1997; Fuglie, 2001; Fahey, 2005; Pinheiro Ferreira et al., 2008; Kasolo et al., 2010).

Las hojas y frutos jóvenes de $M$. oleifera son consumidos como verdura (fresca o cocida), disecados, molidos como "harinas de Moringa" o en cápsulas (Bonal Ruiz et al., 2012). Sus hojas constituyen una excelente fuente de proteínas, aminoácidos esenciales, vitaminas (A, C y E), $\beta$-caroteno, ácidos fenólicos antioxidantes (ácidos gálico, caféico y clorogénico, entre otros), flavonoides (miricetina, quercetina y kaempferol), taninos, triterpenos, glucosinolatos y minerales como calcio, zinc y hierro (Anwar et al., 2007; Kasolo et al., 2010; Abubakar et al., 2011; Olson \& Fahey, 2011; Nweze \& Nwafor, 2014, Tumer et al., 2015; Vergara-Jimenez et al., 2017).

Kasolo et al. (2010), Nweze \& Nwafor (2014) y Vergara-Jimenez et al. (2017), citan para las hojas la presencia de compuestos antialimentarios con potencial medicinal como saponinas, alcaloides, isotiocianatos (derivados de la hidrólisis de los glucosinolatos) y antraquinonas.

Diferentes extractos obtenidos a partir de las hojas de $M$. oleifera presentan propiedades como anticonvulsivante, antioxidante, antiinflamatorio, hipocolesteromiante, hepatoprotector, hipoglucemiante y anticancerígeno (VergaraJimenez et al., 2017; Gonzalez-Trujano et al., 2018; Aekthammarat et al., 2019).

Las semillas producen aceite comestible, utilizado en la industria cosmética, farmacéutica y como lubricante de altísima calidad. Los desechos del prensado contienen uno de los floculantes o aglutinantes vegetales más potentes que se conocen y pueden ser utilizados con antibacterianos para eliminar la turbidez del agua (Anwar, 2007; Abubakar et al., 2011). Los residuos de las semillas, después de la extracción de aceite y aun las ramas molidas son utilizados como complemento forrajero (Martínez, 1959; Reyes et al., 2006).

Existen en Argentina cinco proyectos presentados ante el Congreso de la Nación por diputados y senadores de las provincias de Salta, Formosa y Santa Fe, relacionados al cultivo de M. oleifera, solicitando al Poder Ejecutivo, disponga promover en las regiones del NOA y NEA, el cultivo de esta especie, de probadas cualidades agroindustriales y alimenticias (Asociación plantadores de $M$. oleifera en Argentina, 2017). Desde el 2018, M. oleifera está incluida en el Código Alimentario Argentino, como hierba para infusión en una dosis de $5 \mathrm{gr}$ diarios de hojas secas por persona adulta/ día, pudiendo adicionarse hasta en un 5\% en yerbas mates compuestas o aromatizadas (Secretarías de Regulación y Gestión Sanitaria y de Alimentos y Bioeconomía, Resolución Conjunta -15/2018modificatoria -Artículos 1192 y 1198).

En cuanto a estudios anatómicos, Metcalfe \& Chalk (1950) citan antecedentes generales para la familia Moringaceae. En tanto para $M$. oleifera, Ronse Decraene et al. (1998) describen la ontogenia y anatomía floral de ejemplares recolectados en Burindi, África. Olson (2001a) describe variaciones morfoanatómicas en tallo y raíz de plantas cultivadas en Estados Unidos. May Ling (2004), describe la presencia de nectarios extraflorales en raquis de individuos cultivados en Hong Kong. Abubakar et al. (2011) estudian variaciones morfológicas y anatómicas en epidermis foliares de ejemplares cultivados en el norte de Nigeria. Muhl et al. (2011) describen variaciones anatómicas foliares en relación al espesor del mesofilo y densidad estomática en individuos sometidos a diferentes regímenes de temperatura en Pretoria, Sudáfrica. Torres Castillo et al. (2013) realizan una breve descripción anatómica de hoja, 


\section{A. I. Ruiz et al. - Anatomía e histoquímica de Moringa oleifera}

raíz y tallo en ejemplares cultivados en México. Subrahmanyam \& Shah (1988) y Sholapur \& Patil (2013), describen para especímenes cultivados en India, características de la corteza de tallos y la presencia de conductos lisígenos, con resinas o gomas ricas en compuestos fenólicos, formados a nivel del floema frente a un evento traumático. Salama (2014) compara la morfología de las hojas y semillas, de tres especies del género Moringa cultivadas en Egipto, entre las cuales se cita a $M$. oleifera.

Teniendo en cuenta las numerosas cualidades de esta especie cultivada en todo el mundo y que no se registran estudios morfológicos, anatómicos e histoquímicos para genotipos cultivados en Argentina; se plantea como objetivo estudiar la arquitectura, anatomía e histoquímica foliar y caulinar de ejemplares de M. oleifera, cultivados en la provincia de Tucumán, Argentina, señalando caracteres de valor diagnóstico para su identificación. Estudios de este tipo son relevantes en el control de calidad de productos elaborados con las partes aéreas de esta especie, así como para la separación y caracterización de los principios activos.

\section{Materiales y Métodos}

\section{Material vegetal}

Ejemplares de $M$. oleifera fueron recolectados de un cultivo en la localidad de Los Nogales, depto. Tafí Viejo, provincia de Tucumán, Argentina. Se seleccionaron 5 individuos al azar; de cada uno se tomaron 10 hojas completas y fragmentos de tallos correspondientes al primer o segundo entrenudo desde el ápice foliar orientación norte.

El material fue ingresado al herbario de la Fundación Miguel Lillo, ARGENTINA. Prov. de Tucumán, Dpto. Tafi Viejo, $26^{\circ} 73,79$ ' 10"S $65^{\circ}$ 22,64' 70" O, 591 msnm, 01/XII/2017, Mercado M. I., Ruiz A. I. y Ponessa G. S/N (LIL).

\section{Microscopía óptica}

Las muestras fueron fijadas en FAA (ácido acético, formol, agua y alcohol 1:2:7:10). Para estudios histoquímicos parte de las muestras fueron conservadas frescas en heladera para su inmediata utilización.

Para el estudio de la epidermis y la venación foliar, se realizaron diafanizados del folíolo apical y folíolos medios, según la técnica de Dizeo de Strittmater (1973). En la descripción de la venación foliar se utilizó la terminología de Hickey (1974, 1979) y Ellis et al. (2009). Para la clasificación de los estomas se usó la terminología propuesta por Dilcher (1974).

Los cortes histológicos de lámina del folíolo, raquis primario, secundario y terciario (en su sección media), pecíolo (sección proximal, media y distal), nectarios extraflorales y tallo, se obtuvieron montado muestras de aproximadamente $2 \mathrm{~mm}$ en soportes de cera odontológica, que posteriormente fueron seccionadas con micrótomo rotativo Minot (20-30 $\mu \mathrm{m}$ de espesor). Los cortes fueron decolorados en hipoclorito de sodio al $50 \%$, posteriormente lavados y teñidos con violeta de cresilo, safranina o tinción doble sucesiva azul astra-safranina (Luque et al. 1996) y montados en agua-glicerina (1:1) (D’Ambrogio de Argüeso, 1986; Zarlavsky, 2014).

Para estudios histoquímicos, los cortes fueron sometidos a los siguientes reactivos: rojo de rutenio para pectinas, lugol (IK) y observación bajo luz polarizada para la detección de almidón y oxalatos, azul de toluidina para mucílagos, ácido periódicoreactivo de Shiff (PAS) para otros carbohidratos, sudán IV para lípidos, fucsina ácida y ácido pícrico para proteínas, cloruro férrico para fenoles, reactivo de Dragendorff para alcaloides, reactivo de Liberman-Bouchard para triterpenos y esteroides, vainillin $\mathrm{HCl}$ y vainillin sulfúrico para taninos y saponinas respectivamente y reactivo de Nadi (nafthol y $\alpha$-dimetil-p-fenilenediamina) para aceites esenciales y terpenos (Merck, 1980; D’Ambrogio de Argüeso, 1986; Zarlavsky, 2014).

Se utilizó un microscopio óptico Carl Zeiss Lab. A1 Axiolab con cámara adosada AxioCam ERc 5s Zeiss. Las mediciones de los tejidos se realizaron utilizando el programa Axio Vision release 4.8.2 (Carl Zeiss, Oberkochen, Germany).

Para cada muestra foliar se analizaron 5 campos ópticos al azar y se calculó la densidad, longitud y latitud de estomas y tricomas ubicados en ambas epidermis $(\mathrm{n}=25)$.

\section{Microscopía electrónica de barrido (MEB)}

Se tomaron muestras de lámina y NEF presentes en la base del pecíolo, a nivel del raquis en la inserción de los peciólulos y en la base de los folíolos. Las mismas fueron fijadas en glutaraldehído fosfato $5 \%$ según Karnovsky (1965), se deshidrataron pasando por una serie de alcoholes y acetona, se secaron 
mediante punto crítico con $\mathrm{CO}_{2}$ y posteriormente se recubrieron con oro-paladio. Las observaciones fueron realizadas con MEB ZEISS SUPRA-55 VP (field emission scanning electron microscope FESEM) en el Centro de investigaciones y servicios de microscopia electrónica (CISME, CONICETUNT).

\section{Resultados}

\section{Morfología foliar}

Moringa oleifera presenta hojas de hasta $60 \mathrm{~cm}$ de largo, alternas, compuestas, 2-3 (4) pinnadas, de raquis primario, secundario y terciario articulados, (2-) 5-9 (-11) pares de folíolos, de disposición opuesta, $0,9-1,75(-2,5) \mathrm{cm}$ de largo x 0,5-1,8 cm de ancho, verde oscuro en el haz, verde amarillento en el envés, pulvinuladas a nivel de pecíolo y peciólulos (Fig. 1A-B). Folíolos ovados a obovados, margen entero, ápice obtuso, base asimétrica decurrente, lámina de textura membranácea.

Presenta campos glandulares en las hojas, los cuales son intensamente visitados por hormigas. Los mismos están constituidos por NEF estipitados de tonalidad verdosa, tricomas glandulares y eglandulares. La distribución de los mismos y sus características se detallan en la Tabla 1 y en la Fig. 1C-J.

\section{Arquitectura foliolar}

Venación de tipo: pinnada, camptódroma y broquidódroma. La vena primaria presenta recorrido derecho, algo curvada hacia el ápice, a partir de la porción media distal (Fig. 2A).

Las venas secundarias son broquidódromas festoneadas. El espacio entre ellas es irregular. Las secundarias de posición basal y media forman ángulo moderado $\left(45^{\circ}-65^{\circ}\right)$ y las superiores presentan ángulo casi recto a recto $\left(80^{\circ}-100^{\circ}\right)$. Algunas de ellas, dicotomizadas (Fig. 2A). Se observan venas secundarias decurrentes (Fig. 2B).

Las venas terciarias son de tipo: epimedial, intercostal y exterior. La exterior formando lóbulos (Fig. 2B). Venas cuaternarias de trayectoria al azar (Fig. 2A-B).

Areolación presente de desarrollo moderado. Areolas dispuestas al azar y de forma irregular. Vénulas libres o ramificadas (Fig. 2C). La venación última marginal es incompleta (Fig. 2C).
Anatomía e histoquímica de la lámina del foliolo

En vista superficial $M$. oleifera presenta ambas epidermis de células poligonales, con paredes anticlinales levemente curvadas (Fig. 3A-D). Las células epidérmicas adaxiales son de mayor tamaño que las epidérmicas abaxiales (Fig. 3C-D). La cutícula es delgada; con espesores de $1,90 \pm 0,38 \mu \mathrm{m}$ y 1,20 $\pm 0,17 \mu \mathrm{m}$, adaxial y abaxial, respectivamente; se encuentra cubierta con ceras epicuticulares en forma de escamas (Fig. 3A-B).

Ambas epidermis son unistratas con espesores de $18,37 \pm 4,75 \mu \mathrm{m}$ y $10,80 \pm 1,34 \mu \mathrm{m}$ adaxial y abaxial, respectivamente. Presentan tricomas eglandulares, unicelulares, adpresos, de ápice agudo a redondeado, de $94,71 \pm 24,35 \mu \mathrm{m}$ y $256,17 \pm 55,91 \mu \mathrm{m}$ de long. para la epidermis adaxial y abaxial respectivamente (Fig. 3A, C-D), siendo más frecuentes en la adaxial. Las células epidérmicas, que rodean la base del tricoma, se disponen radialmente presentando aspecto actinocítico (Fig. 3A-C). La hoja es anfiestomática, con aparatos estomáticos de tipo actinocítico y anomocítico; siendo este último el más frecuente (Fig. 3B-D). Las células oclusivas presentan reborde cuticular a nivel del ostíolo y se encuentran hundidas con respecto a las epidérmicas que las rodean (Fig. $3 \mathrm{~A}-\mathrm{B}, \mathrm{D})$, miden $28,30 \pm 3,59 \mu \mathrm{m}$ de long. por 18,51 $\pm 2,45 \mu \mathrm{m}$ de lat. y $28,26 \pm 2,57 \mu \mathrm{m}$ de long. por 21,51 $\pm 1,52 \mu \mathrm{m}$ de lat. para la epidermis adaxial y abaxial, respectivamente. La densidad estomática es de $28 \pm 3$ / $\mathrm{mm}^{2}$ para la epidermis adaxial y de $117 \pm 14 / \mathrm{mm}^{2}$ para la epidermis abaxial.

En sección transversal el contorno de la lámina presenta márgenes rectos y vena media prominente hacia el hipófilo (Fig. 3E). La cutícula es delgada, con espesores de $1,90 \pm 0,38 \mu \mathrm{m}$ y $1,20 \pm 0,17 \mu \mathrm{m}$, adaxial y abaxial respectivamente. Ambas epidermis son unistratas con espesores de 18,37 $\pm 4,75 \mu \mathrm{m}$ y $10,80 \pm 1,34 \mu \mathrm{m}$ adaxial y abaxial respectivamente. El mesofilo es dorsiventral constituido por 1-2 estratos de parénquima en empalizada, con un espesor promedio de 49,16 \pm 7,52 $\mu \mathrm{m}$ y tres-cuatro estratos de parénquima esponjoso laxo con células braquiformes, de 60,36 $\pm 6,89 \mu \mathrm{m}$ de espesor (Fig. 3F). En el parénquima esponjoso se observan idioblastos con drusas de oxalato de calcio (Fig. 3F). Entre ambos tejidos parenquimáticos se encuentra el parénquima paravenal. A nivel de la vena media, se observa un único haz vascular colateral; hacia la superficie adaxial presenta parénquima en empalizada continuo, en tanto hacia la cara abaxial, sub-epidérmicamente 


\section{A. I. Ruiz et al. - Anatomía e histoquímica de Moringa oleifera}
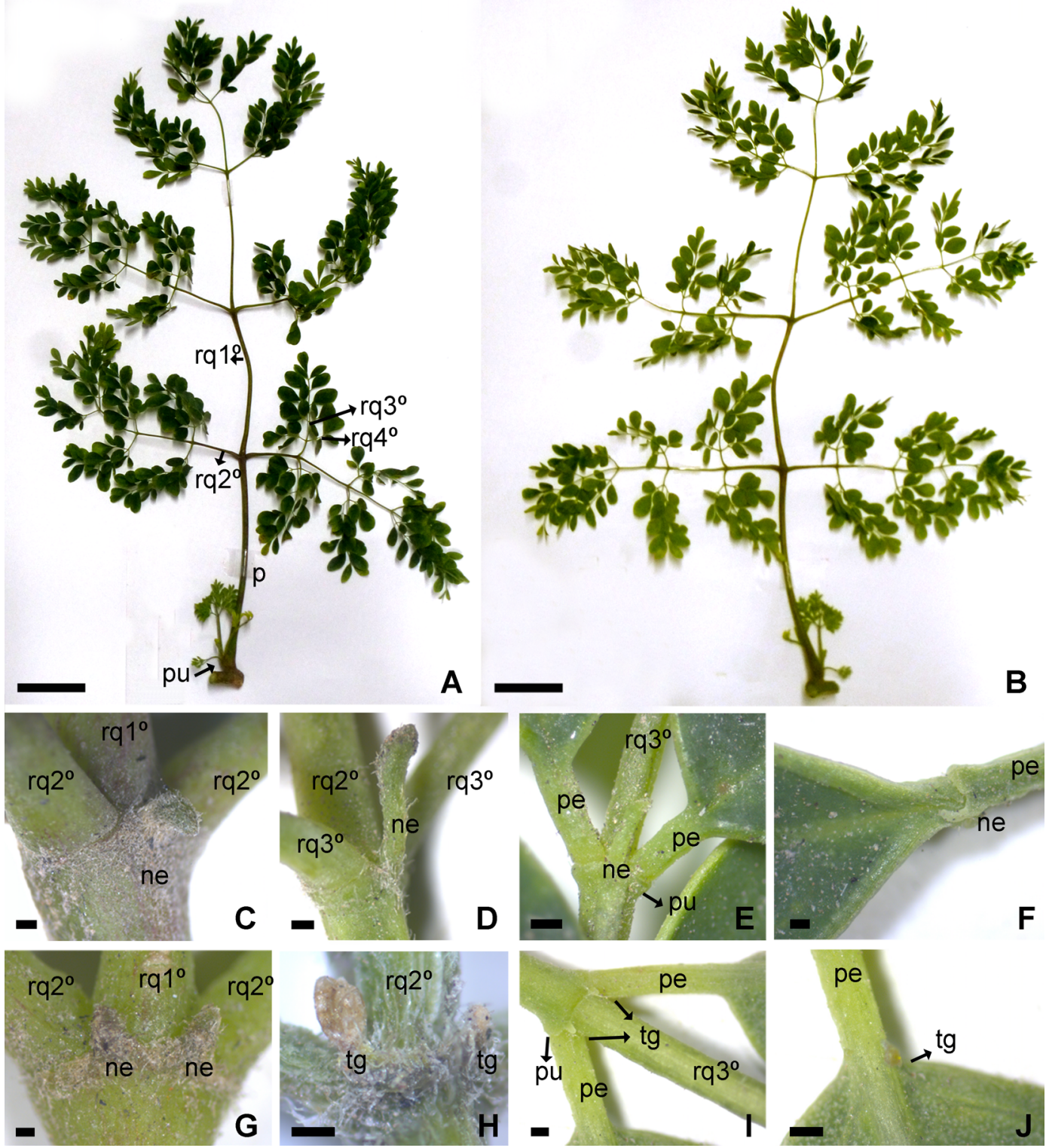

Fig. 1. Moringa oleifera. Hoja compuesta. A: Haz. B: Envés. C, G: Raquis primario en unión de pares de raquis secundarios, vista adaxial y abaxial respectivamente. $\mathbf{D}, \mathbf{H}$ : Raquis secundario en unión de pares de raquis terciarios, vista adaxial y abaxial respectivamente. E, I: Raquis terciario en unión de pares de peciólulos, vista adaxial y abaxial respectivamente. F, J: Base de la lámina del foliólulo terminal en unión al peciólulo, vista adaxial y abaxial respectivamente. Abreviaturas= ne: nectario extrafloral; p: pecíolo; pe: peciólulo; pu, pulvínulo; rq1 ${ }^{\circ}$ : raquis primario; rq2 $2^{\circ}$ : raquis secundario; rq3 $3^{\circ}$ : raquis terciario; rq4 $4^{\circ}$ : raquis cuaternario; tg: tricoma glandular. Escalas= A-B: $5 \mathrm{~cm}$; C: $500 \mu \mathrm{m}$; D-J: $200 \mu \mathrm{m}$.

se observan tres-cinco estratos de colénquima angular-laminar (Fig. 3E). Los haces vasculares correspondientes a las venas de menor orden, son colaterales con vaina parenquimática (Fig. 3F).
En tejidos frescos sin tinción, a nivel del parénquima fundamental próximo a la vena media, se observaron células idioblásticas con contenido ligeramente ámbar (Fig. 4A). La cutícula y el mesofilo presentaron 
Tabla 1. Distribución de campos glandulares en hojas de Moringa oleifera.

\begin{tabular}{|c|c|c|c|c|c|}
\hline \multirow{2}{*}{ Lugar de la hoja } & \multirow{2}{*}{ Detalles } & \multirow{2}{*}{ Superficie } & \multicolumn{3}{|c|}{ Composición } \\
\hline & & & NEF & T. gland. & T. egland. \\
\hline \multirow{2}{*}{ Raquis primarios } & \multirow{2}{*}{$\begin{array}{l}\text { Unión de pares } \\
\text { de raquis } 2^{\circ}\end{array}$} & Adaxial & 1 & - & + \\
\hline & & Abaxial & 2 & - & + \\
\hline \multirow{2}{*}{ Raquis secundarios } & \multirow{2}{*}{$\begin{array}{l}\text { Unión de pares } \\
\text { de raquis } 3^{\circ}\end{array}$} & Adaxial & 1 & - & + \\
\hline & & Abaxial & - & + de a pares & + \\
\hline \multirow[b]{2}{*}{ Raquis terciarios } & \multirow{2}{*}{$\begin{array}{l}\text { Unión de pares de } \\
\text { raquis cuaternarios }\end{array}$} & Adaxial & 1 & - & + \\
\hline & & Abaxial & - & $\begin{array}{c}\text { + de a pares (se } \\
\text { desprenden fácilmente) }\end{array}$ & + \\
\hline \multirow{4}{*}{ Foliolulos } & \multirow{2}{*}{$\begin{array}{l}\text { Unión de peciólulo } \\
\text { con raquis }\end{array}$} & Adaxial & 1 & - & + \\
\hline & & Abaxial & - & $\begin{array}{c}\text { + de a pares (se } \\
\text { desprenden fácilmente) }\end{array}$ & + \\
\hline & \multirow[b]{2}{*}{$\begin{array}{l}\text { Base de la lámina foliar } \\
\text { del foliólulo terminal, } \\
\text { unión con peciólulo }\end{array}$} & Adaxial & 1 & - & + \\
\hline & & Abaxial & - & $\begin{array}{l}\text { + de a pares } \\
\text { (se desprenden } \\
\text { fálcilmente) }\end{array}$ & + \\
\hline
\end{tabular}

Abreviaturas=: -: ausencia; +: presencia. T. glang: tricomas glandulares, T.egland: tricomas eglandulares.

contenido de sustancias lipídicas (Fig. 4B). El reactivo de Nadi específico para terpenos resultó en una débil coloración violeta de células parenquimáticas próximas a los idioblastos cristalíferos (Fig. 4C). Celulosa y pectinas de paredes celulares y laminillas medias se identificaron mediante su tinción con rojo de rutenio (Fig. 4D) y azul de toluidina (Fig. 4E). Esta última coloración también reveló la presencia de mucílagos en células idioblásticas de la epidermis adaxial y en idioblastos del parénquima fundamental próximo a la vena media (Fig. 4E), en los cuales se detectó también presencia de compuestos fenólicos (Fig. 4F), taninos y/o saponinas y/o triterpenos (rojo) (Fig. 4I). Se detectaron proteínas en el mesofilo tanto de empalizada como esponjoso (Fig. 4G, H). Del mismo modo se reveló la presencia de alcaloides en células del mesofilo (Fig. 4J). No se detectó presencia de almidón (Tabla 2).

\section{Anatomía e histoquímica de campos glandulares}

Los campos glandulares están constituidos por $1 \mathrm{o}$ 2 NEF estipitados (Fig. 5A-C); acompañados a ambos lados por tricomas glandulares (Fig. 5D-F).

Los NEF presentan un pie o estípite cilíndrico y cabezuela sub-elipsoidal (Fig. 5A-B). En vista superficial, la epidermis, tanto del estípite como de la cabezuela, posee estomas y tricomas eglandulares idénticos a los descriptos para la lámina foliolar. En la región apical-central de la cabezuela del NEF, se observa una invaginación longitudinal adaxial que corresponde al área de secreción (Fig. 5C).

En transcorte, tanto el estípite como la cabezuela de los NEF son de contorno circular a subcircular, presentan cutícula, epidermis unistrata con células convexas y estomas. En posición subepidérmica, posee uno a dos estratos de células con paredes engrosadas de aspecto colenquimático, con idioblastos de contenido ámbar en material fresco sin tinción y coloreados de rojo intenso con safranina (Fig. 5G-I). En la base del nectario, a nivel del pedúnculo, sobre el lado adaxial, inmediatamente por debajo del estrato de células de paredes engrosadas se presentan dos a cuatro estratos de células clorenquimáticas semejantes a un mesofilo en empalizada de células cortas (Fig. 5G). A nivel de la cabezuela se observa una invaginación donde la epidermis está formada por células secretoras columnares, con citoplasma denso, finamente granuloso y núcleo conspicuo, característicamente secretoras. Por debajo de las células columnares se presentan seis estratos de parénquima glandular secretor, formado por células isodiamétricas, con paredes engrosadas, que se disponen sin dejar espacios intercelulares (Fig. 5I).

El sistema vascular está constituido por trazas que se desprenden de los extremos del haz del pecíolo 


\section{A. I. Ruiz et al. - Anatomía e histoquímica de Moringa oleifera}
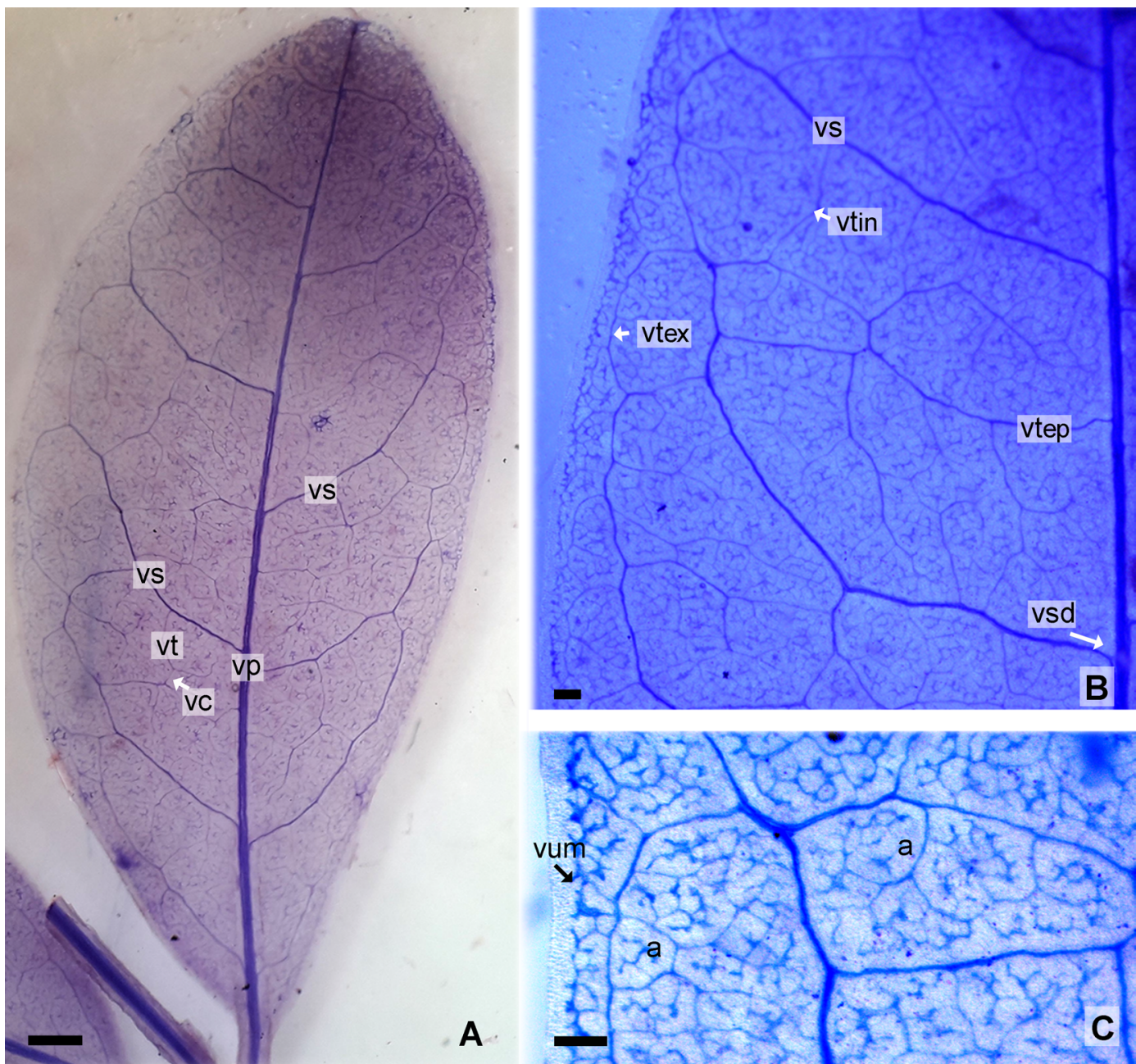

A

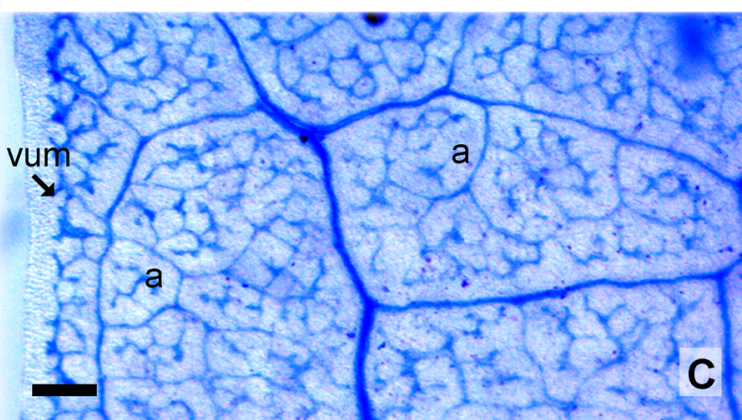

Fig. 2. Moringa oleifera. Arquitectura foliolar en láminas diafanizadas. A: Aspecto general de la lámina. B-C: Detalle de la venación. Abreviaturas= a: aréola; vc: vena cuaternarias; vp: vena primaria; vs: vena secundaria; vsd: vena secundaria decurrente; vt: vena terciaria; vte: vena terciaria epimedial; vtex: vena terciaria exterior; vtin: vena terciaria intercostal; vum: venación última marginal. Escalas= A: $1 \mathrm{~mm}$; B-C: $200 \mu \mathrm{m}$.

foliar e inervan al pie o estípite del NEF formando dos haces colaterales enfrentados (Fig. 5G) que se ramifican hasta desaparecer uno de los mismos en la región media del pie del NEF (Fig. $5 \mathrm{H}$ ). Al entrar a la cabezuela, el haz vascular del estípite del NEF, se ramifica hacia el parénquima, llegando las células terminales del floema hasta un par de estratos por debajo de la epidermis secretora. Los elementos terminales del xilema son traqueoides, células isodiamétricas, que se presentan agrupadas o aisladas, con paredes escalariformes o reticuladas (Fig. 5I).
A lo largo de todo el nectario subepidérmicamente y menos frecuentemente a nivel del parénquima fundamental, se presentan idioblastos cristalíferos con drusas de oxalato de calcio e idioblastos de contenido ámbar (en material fresco sin tinción). En cuanto a la histoquímica, el contenido ámbar resultó positivo a la coloración específica para compuestos fenólicos (Fig. 5J), polisacáridos diferentes al almidón (Fig. 5K-L) y proteínas (Fig. 5M).

Los tricomas glandulares presentan cabeza y pie pluricelulares de hasta $600 \mu \mathrm{m}$ de long. y $300 \mu \mathrm{m}$ de diámetro a nivel de la cabezuela (Fig. $5 \mathrm{~N}$ ). Exhibieron 
Bol. Soc. Argent. Bot. 54 (3) 2019
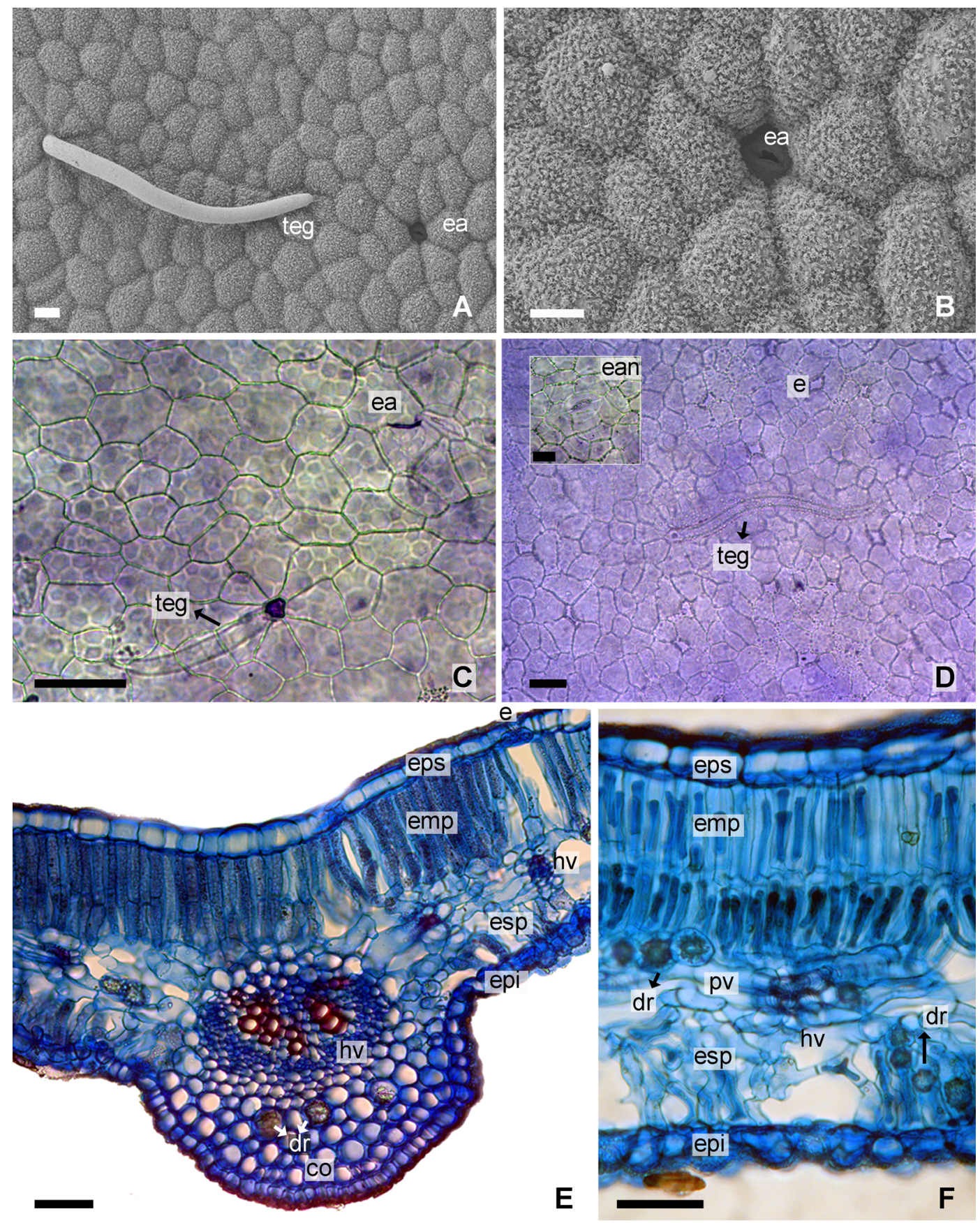

Fig. 3. Moringa oleifera. Anatomía foliar. A-B: Vista superficial (MEB). Ceras epicuticulares en pequeñas escamas. A: Epidermis adaxial con tricoma eglandular y estoma anomocítico. B: Estoma anomocítico C-F: MO. C: Vista superficial de epidermis adaxial con tricoma eglandular y estoma actinocítico. D: Epidermis abaxial, en recuadro detalle de estoma anomocítico, escala $20 \mu \mathrm{m}$. E: Transcorte de folíolo a nivel de la vena media. F: Transcorte de lámina. Abreviaturas= co: colénquima angular-laminar; dr: drusa; e: estoma; ea: estoma actinocítico; ean: estoma anomocítico; emp: mesofilo en empalizada; epi: epidermis abaxial; eps: epidermis adaxial; esp: mesofilo esponjoso; hv: haz vascular; pv: parénquima paravenal; teg: tricoma eglandular. Escalas= A-B: $10 \mu \mathrm{m} ; \mathrm{C}-\mathrm{F}: 50 \mu \mathrm{m}$. 


\section{A. I. Ruiz et al. - Anatomía e histoquímica de Moringa oleifera}

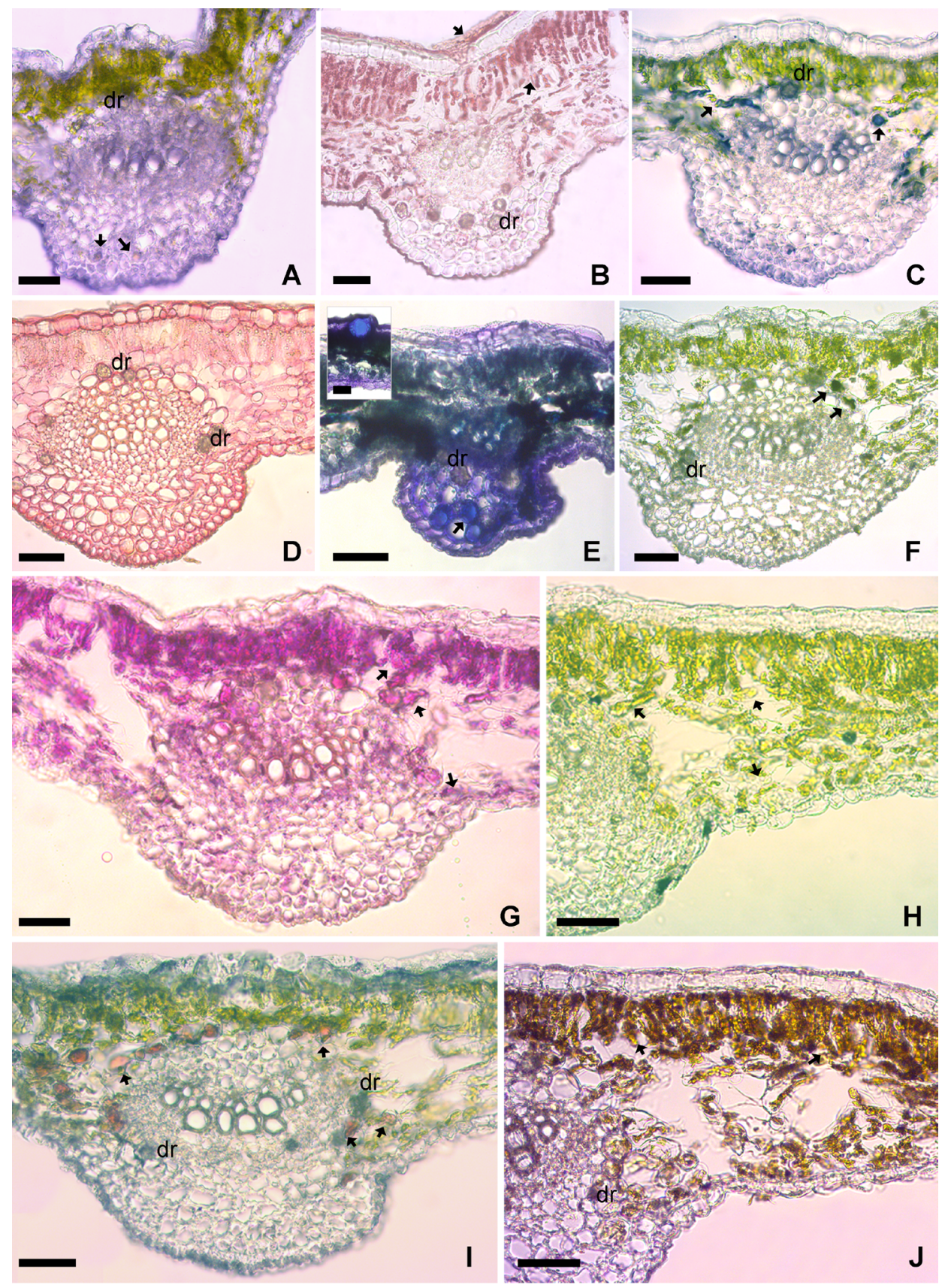

Fig. 4. Moringa oleifera. Histoquímica en transcorte foliolar a nivel de la vena media. A: Material fresco sin tinción donde se observa idioblasto de contenido ámbar (flecha). B-J: Reacciones positivas. B: Sudan IV: lípidos (rojo, flecha) a nivel de cutículas y mesofilo (empalizada y esponjoso). C: Reactivo de Nadi: terpenos (azul violáceo, flecha). D: Rojo de rutenio: celulosa y pectinas de paredes celulares. E: Azul de toluidina: mucilagos en células idioblásticas (flecha). Detalle de transcorte en lámina, escala $20 \mu \mathrm{m}$. F: Cloruro férrico: compuestos fenólicos (pardo verdoso, flecha). G-H. Fucsina ácida y ácido pícrico: proteínas en mesofilo (parénquima en empalizada y esponjoso; flechas). I. Vainillin clorhídrico/sulfúrico y reactivo de LibermanBouchard: taninos, saponinas y/o triterpenos respectivamente (coloración rojiza, flecha). J. Reactivo de Dragendorff: alcaloides (color ladrillo, flecha). Abreviaturas $=\mathrm{dr}$ : drusa. Escalas $=\mathrm{A}-\mathrm{J}: 50 \mu \mathrm{m}$. 
Tabla 2. Test histoquímicos ensayados en Moringa oleifera.

\begin{tabular}{|c|c|c|c|c|c|c|c|c|}
\hline Reactivo & Compuesto & Foliolo & Raquis & Peciolo & Tallo & Nectario & $\begin{array}{c}\text { Tric. } \\
\text { glandular }\end{array}$ & $\begin{array}{l}\text { Conducto } \\
\text { secretor }\end{array}$ \\
\hline Rojo de rutenio & Pectinas & + & - & + & + & - & + & + \\
\hline Azul de toluidina & Mucílagos & ++ & + & + & + & + & + & + \\
\hline PAS & Carbohidratos & - & - & - & - & - & + & - \\
\hline Lugol (IK) & Almidón & - & + & + & + & + & - & - \\
\hline Luz polarizada & Almidón y oxalatos & + & + & + & + & + & - & - \\
\hline Sudan IV & Lípidos & ++ & - & - & - & - & - & + \\
\hline Fucsina ácida & Proteínas & ++ & + & + & + & + & - & ++ \\
\hline Ácido pícrico & Proteínas & ++ & + & + & + & + & - & + \\
\hline Cloruro férrico & Fenoles & + & + & + & ++ & + & - & - \\
\hline Vainillin $\mathrm{HCl}$ & Taninos & + & - & - & + & - & - & - \\
\hline Vainillin Sulfúrico & Saponinas & ++ & - & - & + & - & - & - \\
\hline Reactivo de Nadi & $\begin{array}{c}\text { Aceites esenciales } \\
\text { y terpenos }\end{array}$ & + & - & - & - & - & - & - \\
\hline \multirow{2}{*}{ Liberman-Bouchard } & Triterpenos (rojizo) & + & - & - & - & - & - & - \\
\hline & Esteroides (azul verdoso) & - & - & - & - & - & - & - \\
\hline Dragendorff & Alcaloides & + & - & - & + & - & - & + \\
\hline
\end{tabular}

Abreviaturas=: -: negativo; +: ligeramente positivo; ++: positivo.

coloración positiva para compuestos fenólicos, carbohidratos y proteínas principalmente en el estípite (Fig. 5O-R); y carbohidratos y polisacáridos diferentes al almidón en glóbulos ubicados en las células de la cabeza (Fig. 5P-Q).

\section{Anatomía e histoquímica de peciólulo, raquis y peciolo}

En vista superficial el peciólulo, raquis y pecíolo presentan epidermis constituidas por células poliédricas rectangulares de paredes rectas, con su eje mayor paralelo al eje longitudinal del órgano, estomas anomocíticos (Fig. 6A); cutícula lisa y tricomas eglandulares idénticos a los descriptos para la lámina foliolar.

En sección transversal, peciólulo y pecíolo presentan contorno circular (Fig. 6B, J), en tanto en los raquis $\left(1^{\circ}, 2^{\circ}, 3^{\circ}\right.$ y $\left.4^{\circ}\right)$ es circular a sub-circular con una ligera prominencia adaxial (Fig. 6G-I). En el transcorte de estas secciones de la hoja, se observa epidermis unistrata de células cuadrangulares. Sub epidérmicamente el peciólulo presenta un estrato de colénquima laminar hacia la cara adaxial y uno a cuatro estratos hacia la cara abaxial, en tanto raquis y pecíolo presentan uno a tres estratos continuos de colénquima angular a laminar. En dichos estratos, se observan idioblastos con contenido ámbar en material fresco sin tinción, los mismos se colorean de rojo intenso con safranina (Fig. 6B, G-J) y presentaron reacción positiva para sustancias de naturaleza fenólicas (Fig. 6C), polisacáridos diferentes al almidón (Fig. 6D) y proteínas (Fig. 6E).

Hacia la cara adaxial del peciólulo y raquis inmediatamente por debajo del colénquima, se presentan dos a cuatro estratos de células clorenquimáticas semejantes a un mesofilo en empalizada de células cortas (Fig. 6G-I). En el pecíolo el parénquima cortical presenta diez a quince estratos celulares, en los que se observan idioblatos cristalíferos con drusas y cristales poliédricos de oxalato de $\mathrm{Ca}$ (Fig. 6 L-M).

En el peciólulo el sistema vascular se encuentra conformado por un haz colateral de disposición central, a veces acompañado por uno o dos haces menores invertidos; se observa parénquima amilífero hacia el polo xilemático (Fig. 6B, F). 


\section{A. I. Ruiz et al. - Anatomía e histoquímica de Moringa oleifera}

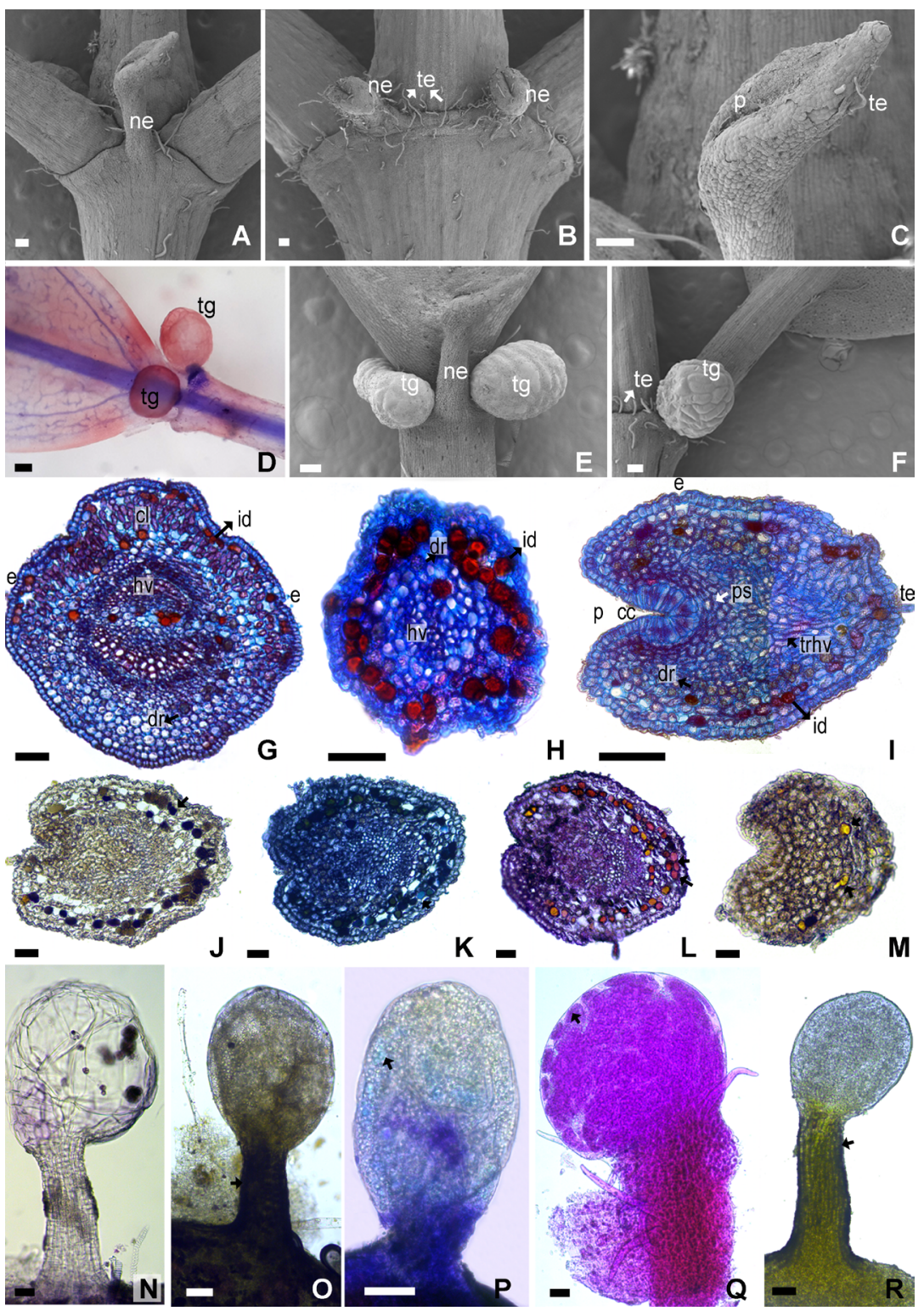

Fig. 5. Moringa oleifera. Campos glandulares. A-C, E- F: MEB. D, G-R: MO. A: Nectario extrafloral (NEF) en superficie adaxial en la unión de raquis $1^{\circ}$ y $2^{\circ}$. B: NEF en superficie abaxial en la unión de raquis $1^{\circ}$ y $2^{\circ}$. C: Detalle de cabezuela del NEF mostrando posición de surco. D: Tricomas glandulares en la base de la lámina foliolar. E: NEF acompañado de tricomas glandulares en la base de la lámina foliolar. F: Tricomas glandulares y eglandulares en la unión del peciólulo y el raquis $3^{\circ}$. G-I: Transcorte de NEF. G: A nivel de la base del pie o estípite. $\mathbf{H}$ : A nivel medio del pie o estípite. I: A nivel de la cabezuela. J-M: Histoquímica de NEF en transcorte a nivel de la cabezuela. N-R: Histoquímica de tricomas glandulares $\mathbf{N}$ : Tricoma glandular, aspecto de material diafanizado sin tinción. $\mathbf{J}, \mathbf{O}: \mathrm{FeCl}_{3}$ : compuestos fenólicos (flecha) en NEF y pie del tricoma glandular. K, L y $\mathbf{P}, \mathbf{Q}$ : Azul de toluidina y PAS: carbohidratos y otros polisacáridos diferentes al almidón, en idioblastos en NEF y glóbulos presentes en células de la cabezuela y pie de tricoma glandular (flecha). M, R: Ácido pícrico: proteínas (flecha) en idioblastos de NEF y en células del pie de los tricomas glandulares respectivamente. Abreviaturas= cc: células columnares; cl: clorénquima; dr: drusa; e: estoma; hv: haz vascular; id: idioblasto; ne: nectario; $p$ : epidermis secretora; ps: parénquima secretor; te: tricoma eglandular; tg: tricoma glandular; trhv: traza de haz vascular. Escalas= A-I: $100 \mu \mathrm{m}$; J-R: $50 \mu \mathrm{m}$. 
Bol. Soc. Argent. Bot. 54 (3) 2019
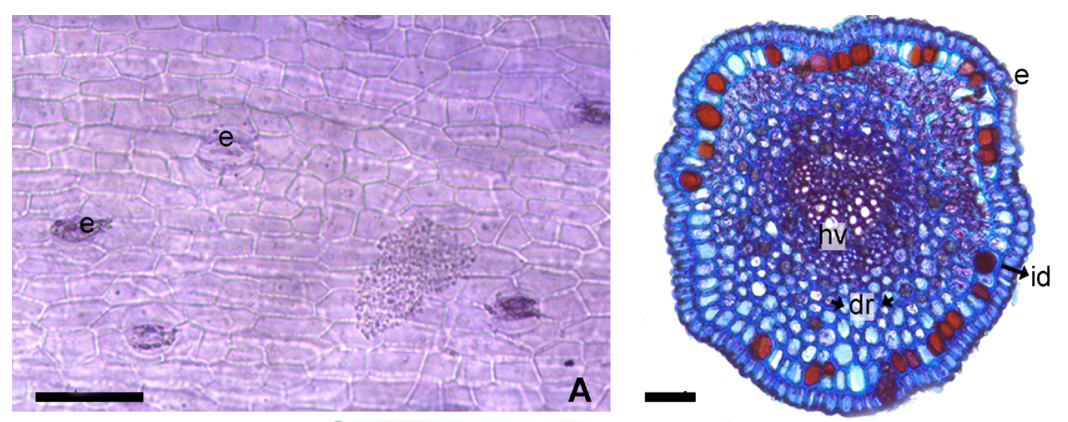

B
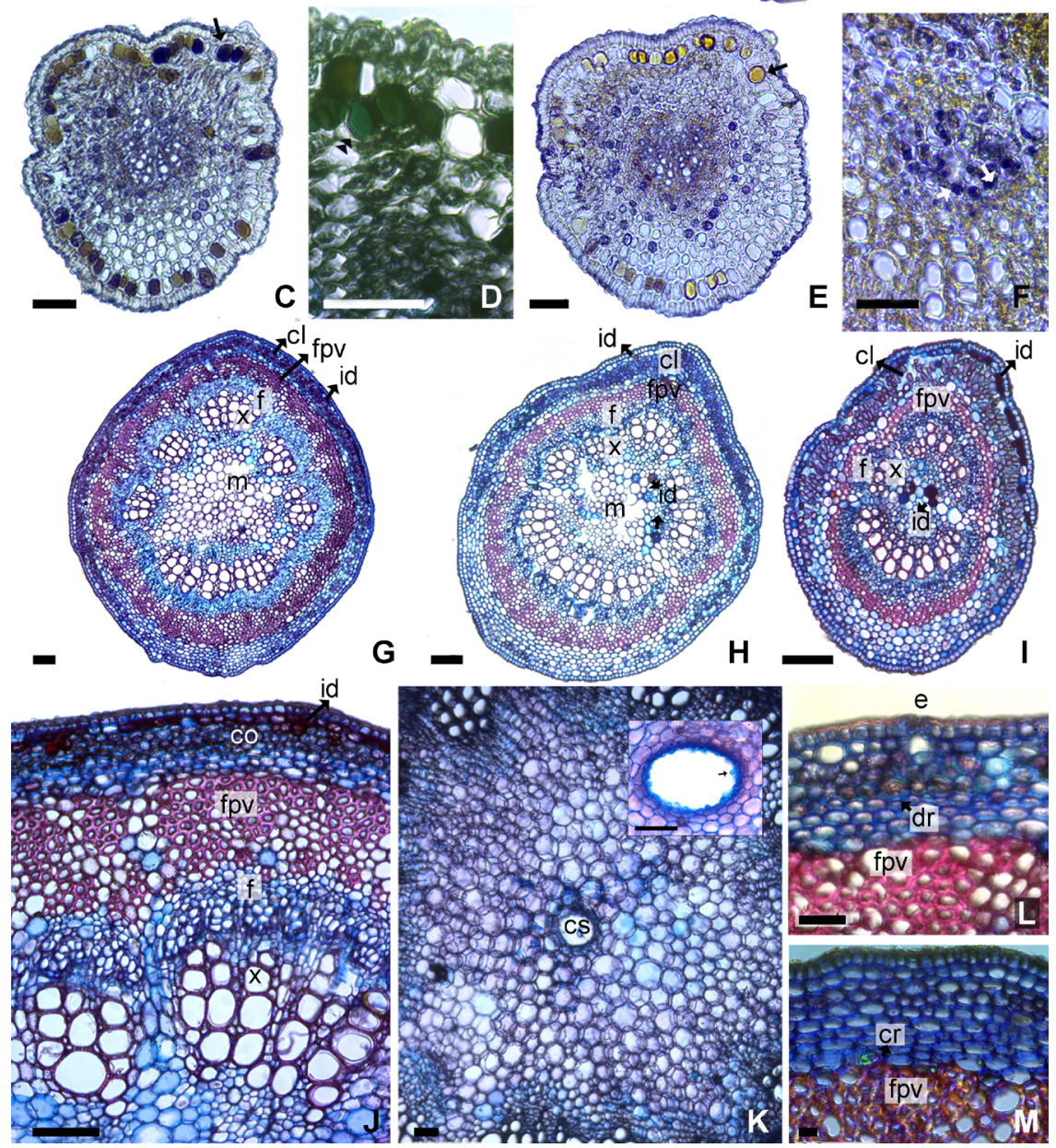

Fig. 6. Moringa oleifera. Anatomía e histoquímica de peciólulo, raquis primario, secundario, terciario y pecíolo. A: Vista superficial de epidermis del peciólulo. B: Transcorte de peciólulo. C-F: Histoquímica de peciólulo. C: Cloruro férrico: idioblastos con compuestos fenólicos (flecha). D: Azul de toluidina: polisacáridos diferentes al almidón (doble cabeza de flecha) en idioblastos. E: Ácido pícrico: proteínas en idioblasto (flecha). F: Lugol: almidón en parénquima amilifero (flecha). G-I: Transcorte de raquis $1^{\circ}$, $2^{\circ}$ y $3^{\circ}$ respectivamente. J: Transcorte de pecíolo. K: Médula del pecíolo con conducto secretor. Detalle de conducto secretor con célula papilosa (flecha), escala $50 \mu \mathrm{m}$. L-M: Córtex del pecíolo con cristales romboidales solitarios y drusas de oxalato de $\mathrm{Ca}$ observados bajo luz blanca y polarizada respectivamente. Abreviaturas= cl: clorenquima; co: colénquima; cr: cristales romboidales solitarios; cs: conducto secretor; dr: drusa; e: estoma; f: floema; fp: fibras perivasculares; hv: haz vascular; id: idioblasto; m: médula; $x$ : xilema. Escalas= A-E: $50 \mu \mathrm{m} ; \mathrm{F}: 20 \mu \mathrm{m} ; \mathrm{G}-\mathrm{K}: 100 \mu \mathrm{m} ; \mathrm{L}-\mathrm{M}: 20 \mu \mathrm{m}$. 


\section{A. I. Ruiz et al. - Anatomía e histoquímica de Moringa oleifera}

Raquis $\left(1^{\circ}, 2^{\circ}, 3^{\circ}\right)$ y pecíolo, presentan haces de disposición radial circundados por un anillo perivascular de tejido esclerenquimático de cinco a siete estratos, y médula parenquimática con idioblastos idénticos a los descriptos para el estrato subepidérmico (Fig. 6G-J). En el pecíolo, la médula parenquimática puede llevar en posición central uno o dos conductos con epitelio secretor uni a bistrato, cuyo estrato interno presenta células papilosas (Fig. 6K).
A nivel del pulvínulo, el anillo de esclerénquima desaparece y el parénquima cortical tiene 20 a 25 estratos celulares.

\section{Anatomía e histoquímica caulinar}

En vista superficial los tallos jóvenes presentan epidermis constituida por células poliédricas cuadrangulares de paredes anticlinales rectas, estomas anomocíticos (Fig. 7A) y tricomas
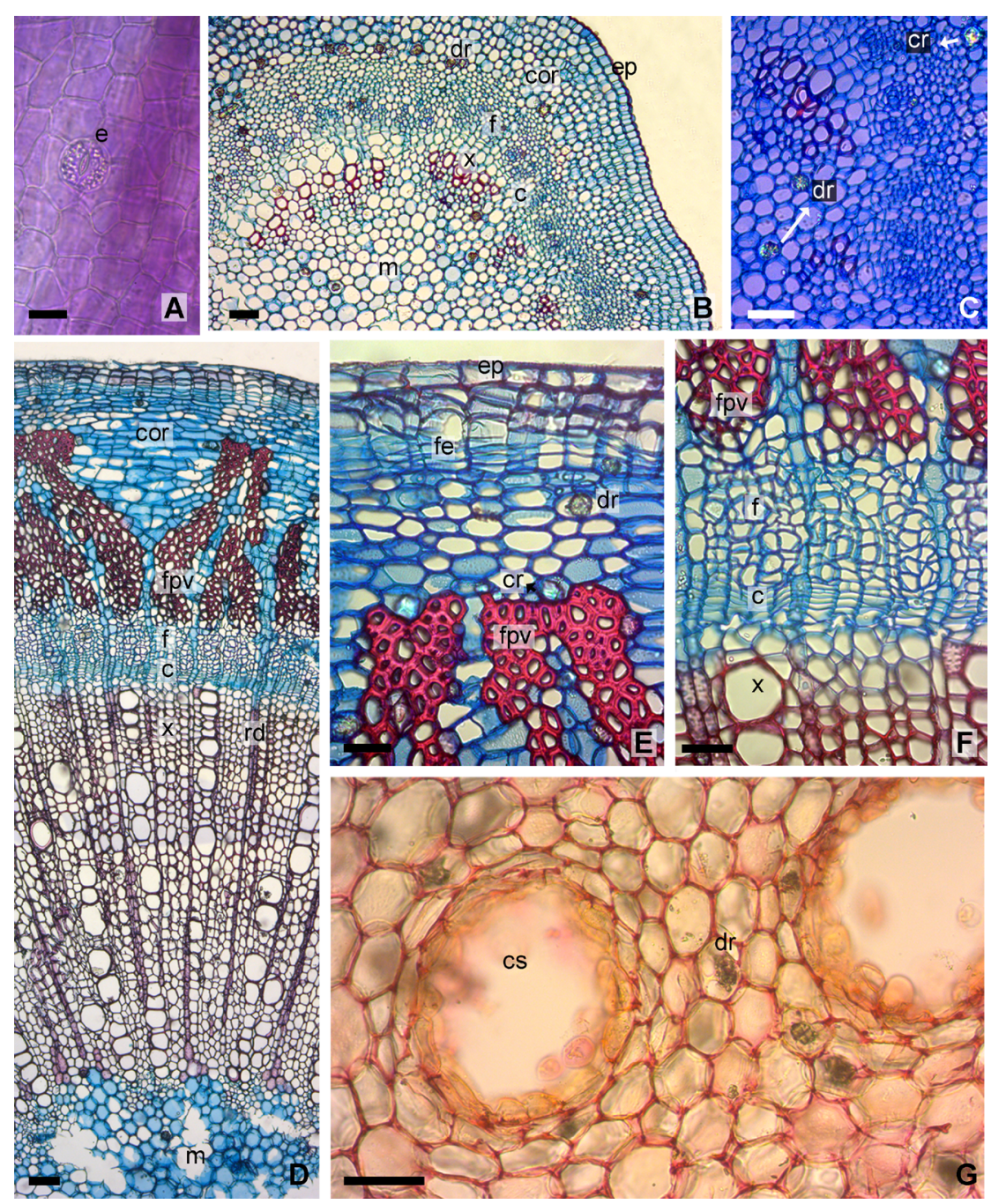

Fig. 7. Moringa oleifera. Anatomía caulinar. A: Vista superficial de epidermis de tallo con crecimiento primario. B: Transcorte de tallo en crecimiento primario con inicio de crecimiento secundario. C: Cristales en forma de drusas de oxalato de $\mathrm{Ca}$, observados con luz polarizada. D: Transcorte de tallo, crecimiento secundario. E. Detalle de epidermis y diferenciación de felógeno. F: Detalle del sistema vascular donde se observa cambium continuo. G: Médula parenquimática con idioblastos con drusas y conductos secretores. Abreviaturas= c: cambium; cor: córtex; cr: cristales; cs: conducto secretor; dr: drusa; e: estoma; ep: epidermis; f: floema; fe: felógeno; fpv: fibras perivasculares; m: médula; rd: radio; $x$ : xilema. Escalas=A: $20 \mu \mathrm{m}$; B-C, E-G: $50 \mu \mathrm{m}$; D: $100 \mu \mathrm{m}$. 

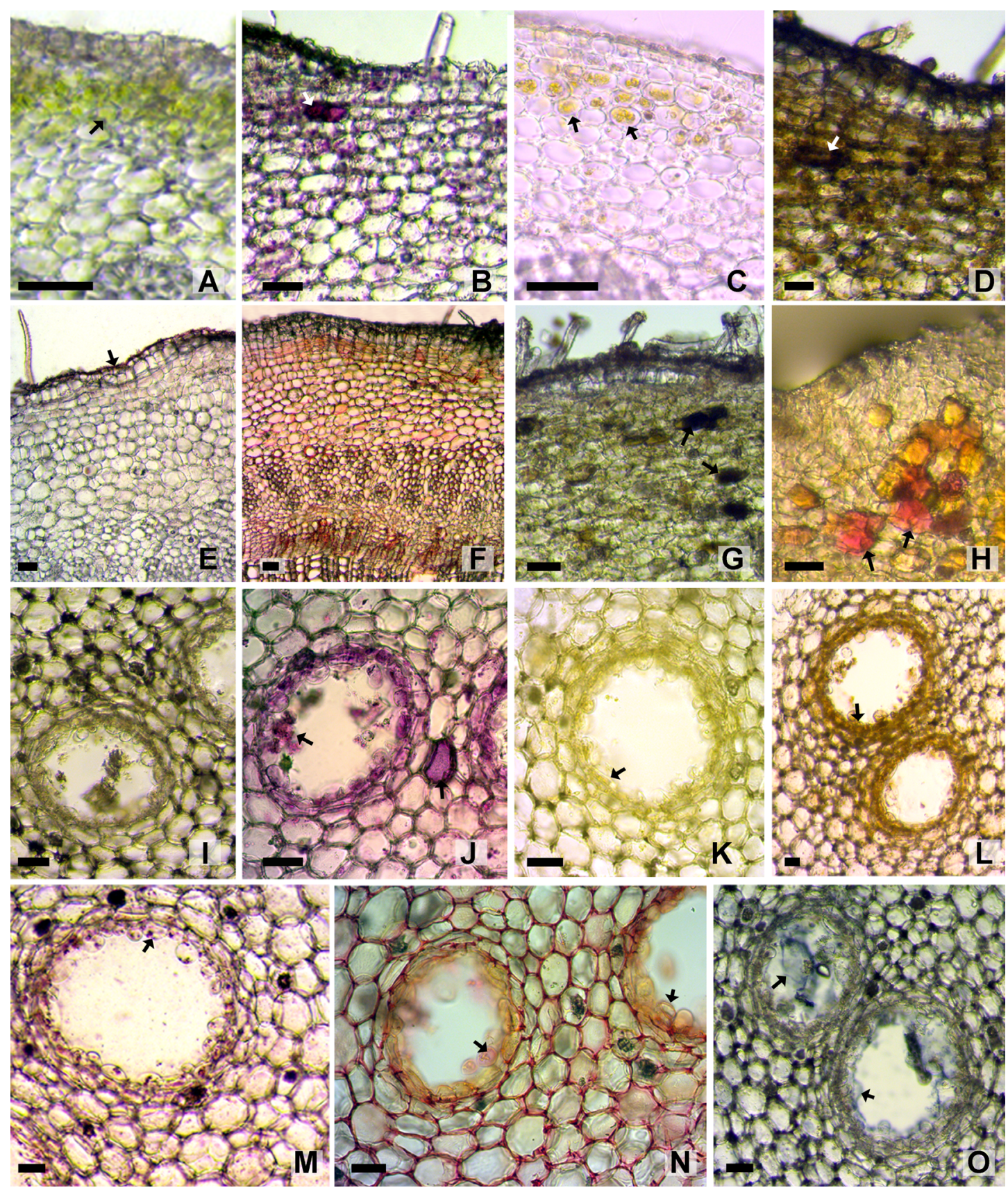

Fig. 8. Moringa oleifera. Histoquímica caulinar. A-H: Idioblastos y estratos corticales del tallo. I-O: Conductos secretores medulares. A, I: Material fresco sin tinción. Observar estratos de clorénquima (flecha) subepidérmico. B, J: Fucsina ácida: proteínas en idioblastos corticales (flecha blanca) y epitelio de conductos secretores (flecha negra). C, K: Ácido pícrico: proteínas (flechas). D, L: Reactivo de Drangendorff: alcaloides (flechas). E, M: Sudan IV: lípidos (flechas) en cutículas y como pequeñas gotas en las células del epitelio secretor. F, N: Rojo de rutenio: celulosa, pectinas y otros azúcares (flechas) en paredes celulares, laminilla media y tenuemente en epitelio secretor. $\mathbf{G}$ : $\mathrm{FeCl}_{3}$ : compuestos fenólicos (flecha) en idioblastos corticales. $\mathbf{H}$ : Vainillin $\mathrm{HCl}$ : taninos (flechas) en idioblastos corticales. O: Azul de toluidina: mucílagos y otros azúcares diferentes al almidón (flechas) en conductos secretores de la médula. Escalas= A-O: $50 \mu \mathrm{m}$. 


\section{A. I. Ruiz et al. - Anatomía e histoquímica de Moringa oleifera}

eglandulares idénticos a los descriptos para la lámina foliolar.

En corte transversal, los tallos de $2 \mathrm{~mm}$ diámetro presentan contorno sub-circular, crecimiento primario, epidermis unistrata de células poliédricas cuadrangulares, parénquima cortical de seis a nueve estratos siendo los dos primeros clorenquimáticos. El sistema vascular está conformado por una eustela en transición a sifonostela ectofloica con cambium interfascicular en desarrollo. La médula parenquimática es amplia, puede presentar uno o dos conductos secretores en posición central, idénticos a los observados en el pecíolo. Tanto en el cótex como en la médula se observan drusas, cristales solitarios de oxalato de Ca (Fig. 7B-C) y ocasionalmente idioblastos con contenido de color ámbar (en material fresco sin tinción).

Tallos de $5 \mathrm{~mm}$ de diámetro o más, en transcorte presentan crecimiento secundario incipiente. La epidermis unistrata persiste en porciones aisladas con cutícula gruesa (Fig. 7D). La peridermis en formación se origina a partir de uno a tres estratos de felógeno, desdiferenciado del parénquima subepidérmico (Fig. 7E). El córtex presenta 1012 estratos de parénquima; en los dos estratos subperidérmicos se observan, ocasionalmente, idioblastos con contenido color ámbar y drusas. El sistema vascular, presenta estructura secundaria típica con xilema y floema en anillos concéntricos (Fig. 7D), se encuentra delimitado por un anillo de fibras perivasculares las que posteriormente formaran cuñas que alternan con el parénquima cortical (Fig. 7D-F). El floema secundario presenta radios uni a biseriados (Fig. 7F) que en ocasiones pueden contener drusas o cristales romboidales solitarios de oxalato de $\mathrm{Ca}$. En el xilema los vasos se encuentran organizados en hileras con radios parenquimáticos uni a biseriados. La médula parenquimática es amplia con abundante almidón e idioblastos con drusas, puede presentar uno o dos conductos secretores originados de la estructura primaria (Fig. 7G).

En la Fig. 8 se pueden observar cortes del tallo sin tinción (Fig $8 \mathrm{~A}, \mathrm{I}$ ) y con diversas pruebas histoquímicas. Tanto los idioblastos de contenido ámbar, como los primeros estratos clorenquimáticos del córtex parenquimático, así como las células papilosas del epitelio de los conductos secretores presentaron resultados positivos para la presencia de proteínas (Fig. 8B-C, J-K) y alcaloides (Fig.
8D, L). La cutícula y pequeñas gotas del epitelio secretor de los canales localizados en la médula, presentaron coloración positiva para lípidos (Fig. 8E, M). Pectinas y otros azúcares fueron identificados mediante la coloración con rojo de rutenio en paredes celulares y tenuemente en las células papilosas del epitelio secretor (Fig. 8F, N). Los idioblastos del parénquima cortical exhibieron coloración positiva para compuestos fenólicos (Fig. $8 \mathrm{G}$ ), taninos (Fig. 8H) y saponinas. El contenido del conducto secretor presentó una tenue coloración positiva para la presencia de mucílagos (Fig. 8O) (Tabla 2).

\section{Discusión y Conclusiones}

La descripción de la arquitectura, anatomía e histoquímica foliar y caulinar de M. oleifera, realizada en la presente contribución, profundiza los conocimientos hasta hoy parcializados para la especie.

Se describe por primera vez para el género la presencia de campos glandulares conformados por NEF, tricomas glandulares y eglandulares; y para $M$. oleifera la arquitectura foliolar, anatomía del pecíolo y NEF, e histoquímica de sus órganos vegetativos aéreos.

Se cita la presencia de tricomas eglandulares en ambas epidermis, en contraposición a lo observado por Qaiser (1973) quien describe hojas escasamente tomentosas en el haz y glabras en el envés.

Metcalfe \& Chalk (1950) para la familia Moringaceae, describiendo a $M$. aptera Gaertn.; $M$. concannensis Nimmo y M. pterygosperma Gaertn., citan presencia de células de mirosina, estomas anomocíticos, mesofilo dorsiventral con empalizada ininterrumpida a nivel los haces vasculares, tricomas eglandulares unicelulares de extremo romo, cristales de oxalato de calcio y conductos secretores en tallo. Estos mismos caracteres, fueron observados en el presente aporte para $M$. oleifera. Con los test histoquímicos aquí realizados no se pudo confirmar la presencia de células de mirosina.

Abubakar et al. (2011) y Salama (2014) citan para $M$. oleifera la presencia de aparatos estomáticos anomocíticos, a nivel de las células epidérmicas; en el presente trabajo se describen aparatos estomáticos anomocíticos y actinocíticos, hundidos con respecto a las células epidérmicas típicas. 
Verdcourt (1985) y Abubakar et al. (2011) describen para $M$. oleifera, que las paredes anticlinales de las células epidérmicas pueden variar de rectas hasta profundamente sinuosas (estas últimas generalmente en la epidermis abaxial), del mismo modo describen variaciones en el tamaño y espesor de los folíolos y de las células oclusivas de los estomas. Abubakar et al. (2011) atribuyen estas diferencias a la plasticidad fenotípica de la especie según las condiciones ambientales del sitio de cultivo, puesto de manifiesto en la experiencia realizada por Muhl et al. (2011) en donde describen modificaciones en caracteres morfo-anatómicos foliares debidas al cultivo bajo diferentes regímenes de temperatura. En el presente trabajo todos los ejemplares estudiados de $M$. oleifera presentaron caracteres meso-xeromórficos, epidermis con células de paredes anticlinales levemente curvas, mesofilo dorsiventral, hojas anfistomáticas con ausencia de tejido esclerenquimático y células oclusivas hundidas con respecto a las epidérmicas típicas.

Caracteres como mesofilo dorsiventral con parénquima en empalizada bistrato, haces colaterales y características caulinares observadas en el presente estudio, fueron coincidentes con los descriptos por Torres Castillo et al. (2013), Salama (2014) y Olson (2001a) para ejemplares de M. oleifera cultivados en México, Egipto y Estados Unidos.

Subrahmanyam \& Shah (1988) y Sholapur \& Patil (2013), describen para especímenes de India, la presencia de resinas o gomas ricas en compuestos fenólicos, formados a nivel de floema en tallos de M. oleifera. En el presente trabajo, se detectaron compuestos fenólicos en idioblastos del parénquima cortical caulinar.

En coincidencia con May Ling (2004), se observa presencia de NEF en el raquis y se completa la descripción indicando su ubicación en diferentes posiciones de la hoja (intersección de raquis $1^{\circ}$ y $2^{\circ}$, interesección de raquis $2^{\circ}$ y $3^{\circ}$, intersección de raquis $3^{\mathrm{o}}$ y $4^{\mathrm{o}}$ e intersección de peciólulos y raquis) y su asociación con tricomas glandulares y eglandulares para componer campos glandulares, mencionados por primera vez para el género.

Los NEF estudiados corresponden a la categoría de elevados (Zimmermann, 1932) y vascularizados (Elías, 1983). El citoplasma, denso y granuloso observado en las células del área de secreción, estaría vinculado con una alta actividad metabólica (producción de néctar).
Al describir la anatomía de los NEF de $M$. oleifera, se observa la presencia de engrosamientos en las paredes del parénquima glandular, ubicado por debajo de la epidermis secretora. Evert (2006); Pacini \& Nepi (2007) denominaron a estas células con engrosamientos como «barrier cells», las cuales, constituirían una barrera al transporte apoplástico, favoreciendo el flujo simplástico de la secreción. Fahn \& Shimony (2001), llamaron nectarostomas a aquellos estomas ubicados en la epidermis de los nectarios e involucrados en la exudación de néctar. Dado que no se observó una relación directa entre estomas y el área de secreción de los NEF de $M$. oleifera, se presume que los mismos no actuarían como nectarostomas, estudios posteriores relacionados a la secreción del néctar, podrían confirmarlo.

Mediante técnicas histoquímicas se detectó en hojas de M. oleifera, la presencia de proteínas, compuestos fenólicos, taninos y triterpenos previamente identificados por Anwar et al. (2007), Kasolo et al. (2010), Olson \& Fahey (2011), Nweze \& Nwafor (2014), Tumer et al. (2015) y VergaraJimenez et al. (2017). Saponinas y alcaloides citadas por Kasolo et al. (2010), Nweze \& Nwafor (2014) y Vergara-Jimenez et al. (2017); fueron débilmente detectados en el presente trabajo. Se sugiere la realización de nuevos ensayos para corroborar su abundancia.

Los caracteres de valor diagnóstico para M. oleifera son: campos glandulares formados por tricomas y NEF; conductos secretores en la médula de tallo y pecíolo, idioblastos secretores ricos en azúcares, proteínas, compuestos fenólicos y triterpenos e idioblastos cristalíferos.

Cabe destacar que si bien $M$. oleifera fue incluida en el Código Alimentario Argentino como hierba para infusión (Artículo 1.192, Código Alimentario Argentino, 2018), aún es necesario demostrar los efectos de su consumo sobre la salud humana (Leone et al., 2016). Hasta la fecha todos los ensayos referidos a sus metabolitos activos fueron realizados en modelos animales o in vitro, a partir de plantas cultivadas en otros países, bajo diferentes condiciones ambientales, razón por la cual podrían exhibir diferencias cuantitativas o cualitativas en sus metabolitos bioactivos. Es importante también destacar que no existen ensayos clínicos rigurosos que prueben su eficacia para tratar la desnutrición (Thurber \& Fahey, 2009). 


\section{A. I. Ruiz et al. - Anatomía e histoquímica de Moringa oleifera}

\section{Contribución de los Autores}

Todos los autores han realizado conjuntamente y a partes iguales la colecta de datos, su interpretación y redacción del manuscrito.

\section{Agradecimientos}

Ingenieros Guillermo Juárez y Oscar Dantur por su desinteresada colaboración y facilitar la obtención del material de estudio.

\section{Biblografía}

ABUBAKAR, B., S. MUA'ZU, A. KHAN \& A. ADAMU. 2011. Morpho-anatomical variation in some accessions of Moringa oleifera Lam. from Northern Nigeria. Afr. J. Plant Sci. 5: 742-748.

AEKTHAMMARAT, D., P. PANNANGPETCH \& P. TANGSUCHARIT. 2019. Moringa oleifera leaf extract lowers high blood pressure by alleviating vascular dysfunction and decreasing oxidative stress in L-NAME hypertensive rats. Phytomedicine 54: 9-16. https://doi.org/10.1016/j. phymed.2018.10.023

ANWAR, F., S. LATIR, M. ASHRAF \& A. GILAN. 2007. Moringa oleifera a food plant with multiple medicinal uses. Phytother Res. 21: 17-25. https://doi.org/10.1002/ptr.2023

ASOCIACIÓN PLANTADORES DE MORINGA OLEIFERA. 2017. Disponible en: $<$ https://es-la. facebook.com/Asociacion-Plantadores-De-MoringaOleifera-En-Argentina-1549984148565957/>. [Consulta: Marzo de 2019].

BONAL RUIZ, R., R. RIVERA ODIO \& E. BOLÍVAR CARRIÓN. 2012. Moringa oleifera: una opción saludable para el bienestar. Medisan 16: 1586-1599.

CÁCERES, A., O. CABRERA, O. MORALES, P. MOLLINEDO \& P. MENDIA. 1991. Pharmacological properties of Moringa oleifera. 1: Preliminary screening for antimicrobial activity. $J$ Ethnopharmacol. 33: 213-216. https://doi.org/10.1016/0378-8741(91)90078-R

CÁCERES, A., A. SARAVIA, L. ZABALA \& E. LEON. 1992. Pharmacologic properties of Moringa oleifera. 2: screening for antispasmodic, anti-inflammatory and diuretic activity. J Ethnopharmacol. 36: 233-237. https://doi.org/10.1016/0378-8741(92)90049-W
CÓDIGO ALIMENTARIO ARGENTINO. 2018. Disponible en: https://www.argentina.gob.ar/ anmat/codigoalimentario. [Consulta: Marzo de 2019].

D'AMBROGIO DE ARGÜESO, A. 1986. Manual de Técnicas en Histología Vegetal. Hemisferio Sur S. A., Buenos Aires.

DILCHER, D. 1974. Approaches to the identification of angiosperm leaves. Bot Rev. 40: 1-157. https://doi.org/10.1007/BF02860067

DIZEO DE STRITTMATER, C. 1973. Nueva técnica de diafanización. Bol. Soc. Argent. Bot. 15: 126-129.

ELÍAS, T. S. 1983. Extrafloral nectaries: Their structure and distribution. In BENTLEY, B. \& T. ELÍAS (eds.) Biology of Nectaries, pp. 174-203, Columbia University Press, New York.

ELLIS. B., D. DALY, L. HICKEY, K. JOHNSON, J. MITCHELL, P. WILF \& S. WING. 2009. Manual of Leaf architecture. The New York Botanical Garden Press. New York.

EVERT, R. F. 2006. Esau's Plant Anatomy: meristems, cells, and tissues of the plant body: their structure, function, and development. John Wiley \& Sons, Hoboken, New Jersey. https://doi.org/10.1002/0470047380

FAHN, A. \& C. SHIMONY. 2001. Nectary structure and ultrastructure of unisexual flower of Echallium elaterium (L.) Rich. (Cucurbitaceae) and their presumptive pollinators. Ann Bot. 87: 27-33. https://doi.org/10.1006/anbo.2000.1287

FAHEY, J. W. 2005. Moringa oleifera: a review of the medical evidence for its nutritional, therapeutic, and prophylactic properties. Part 1. Trees for Life Journal 1:5. Disponible en: http://www.TFLJournal. org/article.php/20051201124931586 (Consulta: 14.X.2017).

FUGLIE, L. J. 2001. The miracle tree: The multiple attributes of Moringa. Technical Center for Agricultural and Rural Cooperation, New York.

GONZALEZ-TRUJANO, M. E., C. L. MARTINEZGONZALEZ, M. FLORES-CARRILLO, S.I. LUNANOPHAL, G. CONTRERAS-MURILLO \& V. M MAGDALENO-MADRIGAL. 2018. Behavioral and electroencephalographic evaluation of the anticonvulsive activity of Moringa oleifera leaf non polar extracts and one metabolite in PTZ-induced seizures. Phytomedicine 39: 1-9. https://doi.org/10.1016/j.phymed.2017.12.009

HAINES H. 1922. Botany of Bihar and Orissa. Parte III. Calyciflorae. Adlard \& Son \& West Newman, Londres. 
HICKEY, L. 1974. Clasificación de la arquitectura de las hojas de Dicotiledóneas. Bol. Soc. Argent. Bot. 16: 1-26.

HICKEY, L. 1979. A revised classification of the architecture of dicotyledonous leaves. In: METCALFE, C. \& L. CHALK (eds.), Anatomy of the Dicotyledons. Volúmen I. Second Edition, pp. 17-33 Clarendon Press, Oxford.

KARNOVSKY, M. 1965. A formaldehyde glutaraldehyde fixative of high osmolality for use in electron microscopy. J Cell Biol. 27:137-138.

KASOLO, J., G. BIMENYA, L. OJOK, J. OCHIENG \& J. OGWAL-OKENG. 2010. Phytochemicals and uses of Moringa oleifera leaves in Ugandan rural communities. J. Med. Plants Res. 4: 753-757.

LEONE, A., A. SPADA, A. BATTEZZATI, A. SCHIRALDI, J. ARISTIL \& S. BERTOLI. 2016. Moringa oleifera seeds and oil: characteristics and uses for human health. Int. J. Mol. Sci. 17, 2141. https://doi.org/10.3390/ijms17122141

LUQUE, R., H. SOUSA \& J. KRAUS. 1996. Métodos de coloração de Roeser (1972) - modificado- e Kropp (1972) visando a substituição do azul de astra por azul de alcião 8 GS ou 8 GX. Acta Bot. Bras. 10: 199-212.

https://doi.org/10.1590/S0102-33061996000200001

MAKKAR, H. \& K. BECKER. 1997. Nutrients and antiquality factors in different morphological parts of the Moringa oleifera tree. J Agric Sci. 128: 311-322. https://doi.org/10.1017/S0021859697004292

MARTÍNEZ, M. 1959. Plantas útiles de la flora mexicana. Botas, México D. F.

MAY LING, S. 2004. The occurrence of extrafloral nectaries in Hong Kong plants. Bot. Bull. Acad. Sinica 45: 237-245.

MERCK, E. 1980. Reactivos de coloración para cromatografía en capa fina y en papel. Darmstadt, Alemania.

METCALFE, C. \& L. CHALK. 1950. Anatomy of the Dicotyledons. Clarendon Press, Oxford.

MUHL, Q., E. DU TOIT \& P. ROBBERTSE. 2011. Moringa oleifera (Horseradish Tree) leaf adaptation to temperature regimes. Int J Agric Biol. 13: 1021-1024.

NWEZE, N. \& F. NWAFOR. 2014. Phytochemical, proximate and mineral composition of leaf extracts of Moringa oleifera Lam. from Nsukka, SouthEastern Nigeria. J Pharm Biol Sci. 9: 99-103. https://doi.org/10.9790/3008-091699103

OLSON, M. E. 2001a. Stem and root anatomy of Moringa (Moringaceae). Haseltonia 8: 56-96.
OLSON, M. E. 2001b. Introduction to the Moringa Family. In: FUGLIE, L. J. (ed.), The miracle tree: The multiple attributes of Moringa, pp. 1128. Technical Centre for Agricultural and Rural Cooperation, Wageningen/ Church World Service, New York.

OLSON, M. E. 2002. Combining data from DNA sequences and morphology for a phylogeny of Moringaceae. Syst. Bot. 27: 55-73.

OLSON, M. E. \& S. RAZAFIMANDIMBISON. 2000. Moringa hildebrandtii: A tree extinct in the wild but preserved by indigenous horticultural practices in Madagascar. Adansonia sér. 3 22: 217-221.

OLSON, M. E. \& J. FAHEY. 2011. Moringa oleifera: un árbol multiusos para las zonas tropicales secas. Rev Mex Biodivers. 82: 1071-1082.

PACINI, E. \& M. NEPI. 2007. Nectar production and presentation. In: NICOLSON, S. W., NEPI, M., \& PACINI, E. (eds.), Nectaries and nectar, pp. 167214. Dordrecht: Springer. https://doi.org/10.1007/978-1-4020-5937-7_4

PINHEIRO FERREIRA, P. M.P., D. F. FARIAS, J. T. ABREU OLIVEIRA \& A. F. URANO CARVALHO. 2008. Moringa oleifera: bioactive compounds and nutritional potential. Revista de Nutrição Campinas 21: 431-437. https://doi.org/10.1590/S1415-52732008000400007

QAISER M. 1973. Moringaceae. In: NASIR E. \& S. ALI (eds), Flora of West Pakistán, pp1-4, Fakhri printing press, Karachi.

REYES, N., E. SPÖRNDLY \& I. LEDIN. 2006. Effect of feeding different levels of foliage of Moringa oleifera to creole dairy cows on intake, digestibility, milk production and composition. Livestock Science 101: 24-31.

https://doi.org/10.1016/j.livprodsci.2005.09.010

RONSE DECRAENE, L., J. DE LAET \& E. SMETS. 1998. Floral development and anatomy of Moringa oleifera (Moringaceae): what is the evidence for a Capparalean or Sapindalean Affinity?. Ann. Bot. 82: 273-284. https://doi.org/10.1006/anbo.1998.0677

SALAMA, M. 2014. Morpho-anatomical variations of leaves and seeds among three Moringa species. Life Sci. J. 11: 827-832.

SHOLAPUR, H. P. \& B. M. PATIL. 2013. Pharmacognostic and phytochemical investigations on the bark of Moringa oleifera Lam. Indian J Nat Prod Resour. 4: 96-101.

SUBRAHMANYAM, S. V. \& J. J. SHAH. 1988. The metabolic status of traumatic gum ducts in Moringa 


\section{A. I. Ruiz et al. - Anatomía e histoquímica de Moringa oleifera}

oleifera Lam. Iawa Bulletin 9: 187-195. https://doi.org/10.1163/22941932-90001067

THURBER, M.D. \& J. W. FAHEY. 2009. Adoption of Moringa oleifera to combat under-nutrition viewed through the lens of the "Difusion of Innovations" theory. Ecol Food Nutr. 48: 212-225. https://doi.org/10.1080/03670240902794598

TORRES CASTILLO, J., S. SINAGAWA GARCÍA, G. MARTÍNEZ ÁVILA, A. LÓPEZ FLORES, E. SÁNCHEZ GONZÁLEZ, V. AGUIRRE ARZOLA, R. TORRES ACOSTA, E. OLIVARES SÁENZ, E. OSORIO HERNÁNDEZ \& A. GUTIÉRREZ DÍEZ. 2013. Moringa oleifera: phytochemical detection, antioxidants, enzymes and antifugal properties. Phyton 82: 193-202.

TUMER, T. B., P. ROJAS-SILVA, A. POULEV, I. RASKIN \& C. WATERMAN. 2015. Direct and indirect antioxidant activity of polyphenol- and isothiocyanate-enriched fractions from Moringa oleifera. J Agric Food Chem. 63: 1505-1513. https://doi.org/10.1021/jf505014n

VERDCOURT, B. 1985. A synopsis of Moringaceae. Kew Bulletin 40: 1-23. https://doi.org/10.2307/4108470

VERGARA-JIMENEZ, M., M. M. ALMATRAFI \& M. L. FERNÁNDEZ. 2017. Bioactive Components in Moringa oleifera leaves protect against chronic disease. Antioxidants 6: 91. https://doi.org/10.3390/antiox6040091

ZARLAVSKY, G. 2014. Histología vegetal: Técnicas simples y complejas. Sociedad Argentina de Botánica, Buenos Aires.

ZIMMERMANN, J. 1932. Uber die Extrafloral Nektarien der Angiospermen. Beih. Bot. Centralbl. 49: 99-196. 
